\title{
Olmesartan improves endothelial function in hypertensive patients: link with extracellular superoxide dismutase
}

\author{
Shunichi Takiguchi ${ }^{1,2}$, Makoto Ayaori ${ }^{1}$, Harumi Uto-Kondo ${ }^{1}$, Maki Iizuka ${ }^{1}$, Makoto Sasaki ${ }^{1}$, \\ Tomohiro Komatsu ${ }^{1}$, Bonpei Takase ${ }^{3}$, Tetsuo Adachi ${ }^{4}$, Fumitaka Ohsuzu ${ }^{2}$ and Katsunori Ikewaki ${ }^{1}$
}

Endothelial dysfunction in essential hypertension is an independent predictor for future cardiovascular events. Although inhibition of the renin-angiotensin system (RAS) reportedly improves endothelial function through its effects on oxidative stress and inflammation, questions remain regarding the factors that are pivotal for improvement of endothelial function by RAS inhibition. We therefore performed a prospective, randomized crossover trial in which an angiotensin II type 1 receptor antagonist, olmesartan and calcium channel blocker, amlodipine, were compared in 31 essential hypertensive patients. Results showed that, although both treatments achieved comparable lowering of blood pressure (BP), olmesartan, but not amlodipine, significantly improved endothelial function as evaluated by flow-mediated vasodilation (FMD) in the brachial artery. Although no significant changes in diabetic and lipid parameters were observed with either drug, olmesartan slightly decreased estimated glomerular filtration rate, which, surprisingly, translated into decreased microalbuminuria. In a similar vein, olmesartan reduced serum C-reactive protein and increased urine antioxidant levels compared with baseline, and reduced urine 8-epi-prostaglandin F2 $\alpha$ levels compared with both baseline and amlodipine. Finally, although overall changes in plasma extracellular superoxide dismutase (EC-SOD) levels were not modulated by either treatment, for olmesartan there was a positive correlation between changes in FMD and those in EC-SOD levels. In conclusion, olmesartan improved endothelial function in hypertensive patients independent of its BP-lowering effect, which was due, at least in part, to its antioxidative property. Therefore, olmesartan might provide a greater long-term benefit for hypertensive patients with impaired endothelial function than amlodipine. Hypertension Research (2011) 34, 686-692; doi:10.1038/hr.2011.11; published online 10 February 2011

Keywords: ARB; endothelial dysfunction; EC-SOD; FMD

\section{INTRODUCTION}

Endothelial dysfunction is associated with essential hypertension and other risk factors for cardiovascular disease. ${ }^{1}$ These factors impair vascular function and increase blood pressure (BP), thereby accelerating atherosclerosis. ${ }^{2,3}$ The observation that oxidative stress and/or inflammation reduces nitric oxide (NO) availability in hypertensive patients, ${ }^{4}$ and the growing evidence for the involvement of the renin-angiotensin system (RAS) in endothelial dysfunction has led to a conceptual breakthrough in developing a therapeutic strategy for improving endothelial function in patients at high cardiovascular risk. Both angiotensin converting enzyme inhibitors (ACEIs) and angiotensin II (Ang II) type 1 receptor antagonists (ARB) are essential drugs for such patients, ${ }^{5}$ and have been reported to restore decreased endothelial function by improving NO availability. ${ }^{6}$ However, it is still controversial whether improvement of endothelial function is an effect of the RAS inhibitor class because several investigators were unable to observe such an effect for $\mathrm{ARB}^{7}$ in spite of beneficial effects seen for other classes of antihypertensives. ${ }^{8}$

Basic research has clearly demonstrated that the Ang II-mediated signal transduction pathway induces inflammation and oxidative stress. ${ }^{9,10}$ In the clinical setting, ACEI and ARB reportedly improve endothelial function by increasing endothelium-bound (released by heparin injection) extracellular superoxide dismutase (EC-SOD) activity, ${ }^{6}$ supporting the above observations. In addition, several pathological statuses have been reported to be associated with endothelial dysfunction, such as diabetes, ${ }^{11}$ dyslipidemia $^{12}$ and chronic kidney diseases, ${ }^{13}$ and RAS inhibitors improved endothelial dysfunction under these conditions. Nonetheless, it remains unclear which factors are pivotal to improvement of endothelial function by RAS inhibition in patients with essential hypertension.

${ }^{1}$ Division of Anti-aging, Department of Internal Medicine, National Defense Medical College, Tokorozawa, Japan; ${ }^{2}$ Division of Cardiology, Department of Internal Medicine, Tokorozawa, Japan; ${ }^{3}$ Department of Critical Care Medicine, National Defense Medical College, Tokorozawa, Japan and ${ }^{4}$ Laboratory of Clinical Pharmaceutics, Gifu Pharmaceutical University, Tokorozawa, Japan

Correspondence: Associate Professor M Ayaori, Division of Anti-aging, Department of Internal Medicine, National Defense Medical College, 3-2 Namiki, Tokorozawa 359-8513, Japan.

E-mail: ayaori@ndmc.ac.jp

Received 22 September 2010; revised 13 December 2010; accepted 16 December 2010; published online 10 February 2011 
The aim of this study was to investigate whether an ARB, olmesartan and a calcium channel blocker, amlodipine, improved endothelial function as assessed by measuring endothelium-dependent flow-mediated vasodilation (FMD) of the brachial artery in patients with essential hypertension, and if so, which factors among metabolic, renal, inflammatory and oxidative statuses were associated with improvement of FMD.

\section{METHODS}

\section{Study design and population}

This study was a prospective, randomized crossover trial in which a 4-week pre-study observation period was followed by two sets of a 12-week treatment period. After the observation period, 31 eligible patients ( 4 women and 27 men, mean age $56 \pm 11$ years) were randomized to either olmesartan or amlodipine treatment with crossover to the other drug.

Inclusion criteria were age $\geqslant 20$ and $<75$ years, mild-to-moderate hypertension defined as average seated manual cuff BP of $>140-180 \mathrm{~mm} \mathrm{Hg}$ (systolic BP) or $90-105 \mathrm{~mm} \mathrm{Hg}$ (diastolic BP) measured in the morning at $\sim 0900$ hours. Exclusion criteria included secondary hypertension or uncontrolled BP (systolic BP or diastolic BP of $>180$ or $105 \mathrm{~mm} \mathrm{Hg}$, respectively), or receiving an ARB, ACEI or direct renin inhibitor, pregnancy, history of stroke, acute coronary syndrome or any cardiovascular diseases needing inpatienttreatment within 6 months, end stage renal disease, hepatic dysfunction (either level of aspartate aminotransaminase or alanine aminotransferase exceeding three times normal limits), malignancies or inflammatory diseases.

After being randomly assigned to either of the two groups, for the first 4 weeks, patients received $20 \mathrm{mg}$ olmesartan or $5 \mathrm{mg}$ amlodipine once daily. The patients were asked to visit every 4 weeks to monitor BP/heart rate (HR). The once-daily dose was titrated up to $40 \mathrm{mg}$ olmesartan or $10 \mathrm{mg}$ amlodipine if the BP did not meet $\leqslant 140 / 90 \mathrm{~mm} \mathrm{Hg}$. Other medications including anti-hypertensive, anti-platelet, anti-diabetic or lipid-lowering drugs were maintained throughout the study.

FMD and blood/urine sampling were performed at baseline and after 12 weeks on the treatments. Thereafter, the treatments were switched and the same protocol was applied for another 12 weeks. The study was approved by the ethics committee of National Defense Medical College, and written informed consent was obtained from each subject.

\section{Home and office BP measurement}

Patients were asked to measure their BP once every morning in the sitting position, within $1 \mathrm{~h}$ of waking up, after at least $2 \mathrm{~min}$ of rest, but before taking any drugs or breakfast, and once every evening just before going to sleep. They were asked to record their BP over a 4 -week period ${ }^{14}$ using electronic arm-cuff devices using the cuff-oscillometric method. All such devices available in Japan have been validated and approved by the Ministry of Health, Labor and Welfare, Japan. ${ }^{15}$ Their manufacturers were Omron Healthcare (Kyoto, Japan), A\&D (Tokyo, Japan), Terumo (Tokyo, Japan) and Matsushita Electric Works (Osaka, Japan). The devices were purchased by patients themselves, not provided by doctors involved in the study. All devices used for home BP measurement in Japan are certified as having been adjusted to the Association for the Advancement of Medical Instrumentation standard. ${ }^{15}$ The mean of all measurements recorded over the 4-week period was calculated for each patient and used for the analysis. Office BPs were measured three times consecutively by the auscultatory method with mercury in the sitting position after a rest of at least $2 \mathrm{~min}$, in regularly scheduled visits by physicians.

\section{Assessment of endothelial function}

Endothelial function was assessed by FMD of the brachial artery. After measurement of $\mathrm{BP} / \mathrm{HR}$, FMD was measured non-invasively using a highresolution ultrasound apparatus with a $7.5 \mathrm{-MHz}$ linear array transducer (Aplio SSA-770A, Toshiba, Tokyo, Japan) according to the guidelines of the International Brachial Artery Reactivity Task Force. ${ }^{16}$ All measurements were performed in the morning from 0900 to 1100 hours in a temperaturecontrolled room $\left(25^{\circ} \mathrm{C}\right)$ with the subject in a fasting, resting and supine state. Electrocardiograms were monitored continuously. The subject's dominant arm (right) was immobilized comfortably in the extended position to allow consistent access to the brachial artery for imaging. The vasodilation responses of the brachial artery were observed using a previously validated technique. ${ }^{17}$ For each subject, optimal brachial artery images were obtained between 2 and $10 \mathrm{~cm}$ above the antecubital fossa. First, baseline two-dimensional images were obtained and after measurement of baseline artery diameter, a narrow-width BP cuff was inflated on the most proximal part of the forearm to an occlusive pressure $(200 \mathrm{~mm} \mathrm{Hg})$ for $5 \mathrm{~min}$ to induce hyperemia. The position of the ultrasound transducer was carefully maintained throughout the procedure. The cuff was then deflated rapidly and twodimensional images of the artery were obtained for $60-120 \mathrm{~s}$ after deflation. Using the same method, we measured endothelium-independent vasodilation because of administering nitroglycerin $(0.3 \mathrm{mg})$. The nitroglycerin-mediated vasodilation (NMD) was measured before (baseline) and $5 \mathrm{~min}$ after nitroglycerin administration. Throughout the study, FMD and NMD were examined by two cardiologists who were blinded to the treatment regimen of each subject, using the same ultrasound apparatus and probe set for all measurements. All images were recorded as movie files in a hard disk recorder for later analysis. To measure vasodilator responses in each patient's artery, movies were played back and a $10-20 \mathrm{~mm}$ segment was identified for analysis using anatomic landmarks. To select images reproducibly for the same point in the cardiac cycle, images at peak systole were identified and the diameter of the artery was digitized using a caliper function of the ultrasound apparatus. For each condition (baseline, FMD, baseline before NMD and after NMD), three separate images from three different cardiac cycles were digitized and their average segment diameters were determined. Both FMD and NMD were expressed as percentage change from baseline. The intra- and inter-observer variability (coefficient of covariance) for repeated diameter measurements at baseline and reactive hyperemia or NMD in the brachial artery were both $<3 \%{ }^{17}$

\section{Blood sampling before and after heparin injection and EC-SOD measurement}

Venous blood and urine samples for measurement of biochemical parameters were obtained in the morning after an overnight fast. To obtain post-heparin plasma, blood was drawn 10 min after intravenous heparin $\left(30 \mathrm{unit} \mathrm{kg}^{-1}\right.$ ) injection. Pre- and post-heparin EC-SOD were measured as described below using an enzyme-linked immunosorbent assay. ${ }^{18}$

\section{Other biochemical analyses of blood and urine samples}

Serum total cholesterol, triglycerides, high-density lipoprotein-C, glucose and creatinine levels were determined by standard enzymatic methods. Hemoglobin Alc was determined using high-performance liquid chromatography. Plasma insulin was measured by chemiluminescent enzyme immunoassay. Insulin resistance was evaluated by homeostasis model assessment estimated-insulin resistance according to the method described by Matthews et al. ${ }^{19}$ Serum high sensitivity C-reactive protein (hsCRP) levels were measured using a BNII nephelometer (Dade Behring, Germany).

Urine antioxidative capacity was determined using a commercially available kit (Cayman, Ann Arbor, MI, USA) according to the method reported by Miller et al. ${ }^{20}$ based on the scavenging of ABTS + (2,2' -azinobis-(3-ethylbenzothiazoline-6-sulfonate)) radical cations and evaluated by their reactivity relative to a $1.0 \mathrm{mmoll}^{-1}$ Trolox standard. Urine 8-epi-prostaglandin F2 $\alpha$ (8-epi-PGF2 $\alpha$ ) levels were determined using a commercially available kit (JaICA, Fukuroi, Japan) according to the method of Morrow et al. ${ }^{21}$ The estimated glomerular filtration rate (eGFR) was calculated to assess renal function using the modified three-variable equation for Japanese, as recently proposed by the Japanese Society of Nephrology: eGFR $=194 \times$ serum creatinine $e^{-1.094} \times$ age $^{-0.287} \times 0.739$ (if female). ${ }^{22}$ Urine albumin was detected using an enzyme-linked immunosorbent assay, and the urinary creatinine concentration was measured by a standard laboratory method. Urinary albumin excretion was estimated by calculating the albumin:creatinine ratio. Urine monocyte chemoattractant protein-1 was determined by an enzymelinked immunosorbent assay (R\&D Systems, Minneapolis, MN, USA). 


\section{Statistical analyses}

Statistical analyses were performed using the Stat View Version 5.0 software package (SAS Institute, Cary, NC, USA). Measurements are presented as mean \pm s.d. for parametric variables and median (interquartile range) for non-parametric variables. Differences between two groups were evaluated using the unpaired $t$-test for parametric variables and the Mann-Whitney $U$-test for non-parametric variables. Correlations among changes in variables were evaluated using Pearson's correlation coefficient.

Table 1 Baseline characteristics of study subjects

\begin{tabular}{|c|c|c|}
\hline & $\begin{array}{c}\text { Olmesartan }> \\
\text { amlodipine } \\
(\mathrm{n}=15)\end{array}$ & $\begin{array}{c}\text { Amlodipine > } \\
\text { olmesartan } \\
(\mathrm{n}=16)\end{array}$ \\
\hline Gender, male & 13 & 14 \\
\hline Age, years & $55 \pm 11$ & $56 \pm 11$ \\
\hline Body mass index, $\mathrm{kg} \mathrm{m}^{-2}$ & $25.8 \pm 4.2$ & $24.4 \pm 3.1$ \\
\hline Smoking, $n$ & 6 & 4 \\
\hline Diabetes mellitus, $n$ & 4 & 3 \\
\hline Coronary artery diseases, $n$ & 0 & 1 \\
\hline Ischemic stroke, $n$ & 1 & 1 \\
\hline \multicolumn{3}{|l|}{ Office $B P / H R$} \\
\hline $\mathrm{SBP}, \mathrm{mm} \mathrm{Hg}$ & $152 \pm 15$ & $149 \pm 21$ \\
\hline $\mathrm{DBP}, \mathrm{mm} \mathrm{Hg}$ & $95 \pm 10$ & $91 \pm 14$ \\
\hline $\mathrm{HR}, \mathrm{bpm}$ & $80 \pm 9$ & $81 \pm 18$ \\
\hline \multicolumn{3}{|l|}{ Medication } \\
\hline$\beta$-blockers, $n$ & 0 & 1 \\
\hline Diuretics, $n$ & 1 & 1 \\
\hline Statins, $n$ & 1 & 1 \\
\hline Aspirin, $n$ & 1 & 2 \\
\hline Antidiabetic agents, $n$ & 1 & 0 \\
\hline
\end{tabular}

Abbreviations: $\mathrm{BP}$, blood pressure; bpm, beats per minute; $\mathrm{DBP}$, diastolic $\mathrm{BP} ; \mathrm{HR}$, heart rate SBP, systolic BP.

Values are mean \pm s.d.

\section{RESULTS}

The baseline characteristics of each group (olmesartan or amlodipine) are shown in Table 1. Patients were aged 40-74 years. There were no differences in gender, age, body mass index, smoking status, office BPs, or HR between the groups. The study subjects included seven type 2 diabetic patients among whom, one and two patients experienced coronary artery diseases and ischemic stroke, respectively. As shown in Table 1, a few subjects were taking other medications. These treatments had not been changed since 1 year before the start of this study. There were no significant differences in complications and medications between the groups.

As shown in Table 2, 12 weeks of treatment with olmesartan or amlodipine resulted in significant reductions in both systolic BP and diastolic BP at office as compared with the baseline values. Although there were no changes in HR between before and after treatments, HR was significantly lower after treatment with olmesartan compared with amlodipine. Both drugs significantly reduced home BPs in the morning and before sleep. Olmesartan brought about a significant reduction in the home HR in the morning, similar to that in the office HR. Overall, both treatments produced comparable reductions in office and home BPs as previously reported. ${ }^{23}$ At 12 weeks of treatment, daily doses of olmesartan were $20 \mathrm{mg}$ in 23 subjects, $40 \mathrm{mg}$ in 8 subjects and those of amlodipine were $5 \mathrm{mg}$ in 21 subjects, $7.5 \mathrm{mg}$ in 1 subject and $10 \mathrm{mg}$ in 9 subjects. The resulting mean doses of the drug at follow-up were $25.8 \mathrm{mg}$ for olmesartan and $6.5 \mathrm{mg}$ for amlodipine.

There were no differences in basal and peak diameters of the brachial artery after FMD/NMD among baseline, olmesartan and amlodipine phase results (Table 3). Endothelial function as represented by FMD in our study subjects was $3.9 \pm 3.0 \%$ lower than in healthy subjects. ${ }^{24}$ Interestingly, it was olmesartan, not amlodipine, which significantly increased FMD. In contrast, NMD was unchanged after the treatments. Figure 1 shows individual changes in FMD during the study. Olmesartan increased and decreased FMD in 19 and 12 subjects, respectively. We observed no difference in FMD

Table 2 Blood pressures and heart rate at office and home, and doses of antihypertensives before and after treatments

\begin{tabular}{|c|c|c|c|c|c|c|}
\hline & Baseline & Olmesartan & Amlodipine & P-value & P-value ${ }^{\mathrm{b}}$ & $\mathrm{P}$-value ${ }^{\mathrm{c}}$ \\
\hline \multicolumn{7}{|l|}{ Office } \\
\hline $\mathrm{SBP}, \mathrm{mm} \mathrm{Hg}$ & $151 \pm 18$ & $131 \pm 14$ & $128 \pm 13$ & $<0.001$ & $<0.001$ & 0.4 \\
\hline DBP, $\mathrm{mm} \mathrm{Hg}$ & $93 \pm 12$ & $83 \pm 8$ & $82 \pm 9$ & 0.003 & $<0.001$ & 0.1 \\
\hline $\mathrm{HR}, \mathrm{bpm}$ & $80 \pm 14$ & $74 \pm 12$ & $78 \pm 11$ & 0.1 & 0.5 & 0.04 \\
\hline \multicolumn{7}{|l|}{ Home } \\
\hline \multicolumn{7}{|l|}{ Early morning } \\
\hline $\mathrm{SBP}, \mathrm{mm} \mathrm{Hg}$ & $147 \pm 9$ & $136 \pm 9$ & $134 \pm 9$ & $<0.001$ & 0.001 & 0.09 \\
\hline DBP, $\mathrm{mm} \mathrm{Hg}$ & $90 \pm 11$ & $85 \pm 9$ & $84 \pm 8$ & 0.001 & 0.001 & 0.2 \\
\hline $\mathrm{HR}, \mathrm{bpm}$ & $73 \pm 15$ & $70 \pm 12$ & $71 \pm 12$ & 0.1 & 0.9 & 0.03 \\
\hline \multicolumn{7}{|l|}{ Before sleep } \\
\hline $\mathrm{SBP}, \mathrm{mm} \mathrm{Hg}$ & $144 \pm 13$ & $132 \pm 14$ & $131 \pm 11$ & $<0.001$ & $<0.001$ & 0.1 \\
\hline DBP, $\mathrm{mm} \mathrm{Hg}$ & $88 \pm 11$ & $81 \pm 10$ & $80 \pm 10$ & 0.003 & $<0.001$ & 0.2 \\
\hline $\mathrm{HR}, \mathrm{bpm}$ & $76 \pm 14$ & $74 \pm 12$ & $72 \pm 11$ & 0.08 & 0.2 & 0.4 \\
\hline $\begin{array}{l}\text { Dose of olmesartan/amlodipine at } \\
\text { follow-up, mg per day }\end{array}$ & & $25.8 \pm 9.2$ & $6.5 \pm 2.3$ & & & \\
\hline
\end{tabular}

Abbreviations: bpm, beats per minute; DBP, diastolic BP; HR, heart rate; SBP, systolic BP.

Values are mean \pm s.d.

$\mathrm{BPs}$ and HR at home were recorded every day during period of 1 month before follow-up visit.

a $P$-value of olmesartan treatment $v s$. baseline.

b $P$-value of amlodipine treatment $v s$. baseline.

${ }^{c} P$-value of olmesartan treatment $v s$. amlodipine. 
Table 3 Endothelial function parameters in hypertensive patients at baseline and after treatments

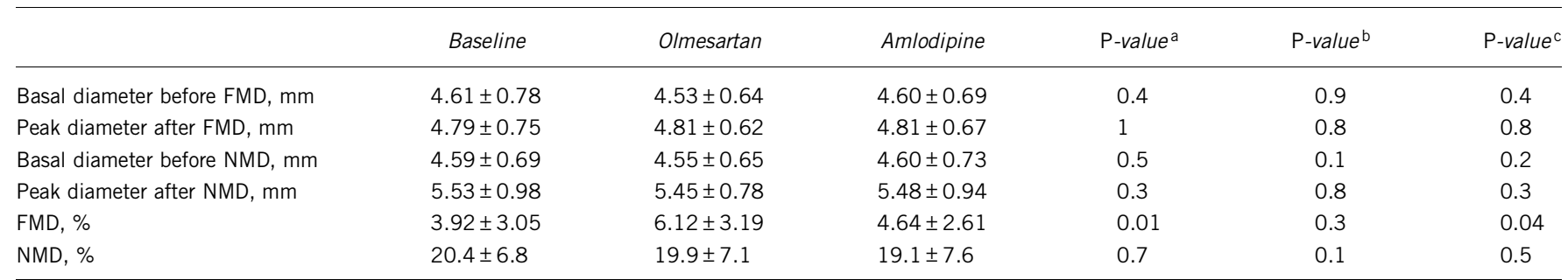

Abbreviations: FMD, flow-mediated vasodilation; NMD, nitroglycerin-mediated vasodilation.

Values are mean \pm s.d.

a $P$-value for olmesartan treatment vs. baseline.

${ }^{\mathrm{b}} P$-value for amlodipine treatment $v s$. baseline.

${ }^{c} P$-value for olmesartan treatment $v s$. amlodipine.

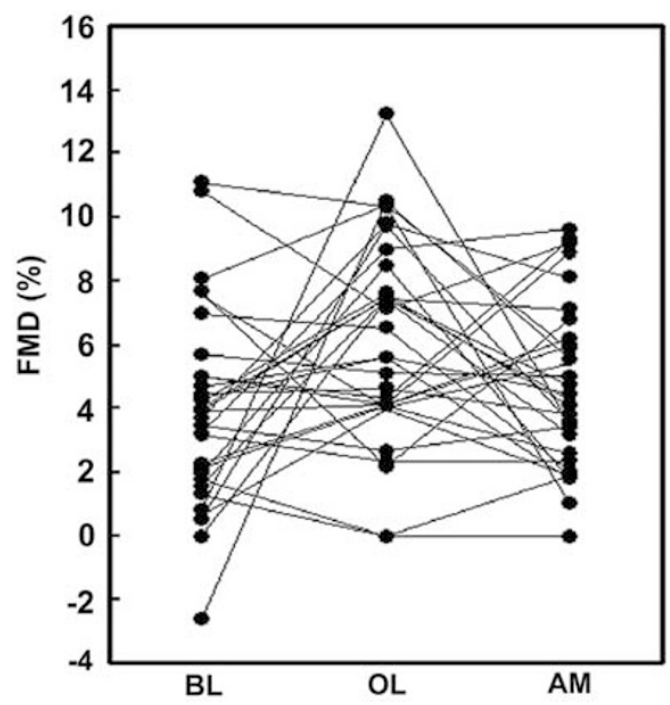

Figure 1 Individual changes in flow-mediated vasodilation (FMD) in brachial artery during study. FMD was measured before (baseline, BL) and after 12 weeks of treatment with olmesartan (OL) or amlodipine (AM).

responses among the subjects with $(n=24)$ or without $(n=7)$ type 2 diabetes (data not shown).

Biochemical parameters are summarized in Table 4. There were no differences in blood and urine parameters among baseline, and olmesartan and amlodipine phase results. Amlodipine significantly reduced fasting plasma insulin levels and olmesartan also tended to reduce levels. However, there were no changes in serum lipids, fasting blood glucose, hemoglobin Alc or homeostasis model assessment estimated-insulin resistance due to or between the two treatments. Olmesartan slightly, but significantly increased serum creatinine levels and consequently decreased eGFR, though amlodipine did not affect these parameters. Serum levels of hsCRP, an anti-inflammatory marker, were significantly decreased by olmesartan, but not amlodipine, an observation consistent with a previous study. ${ }^{25}$ As additional confirmation of the anti-inflammatory property of olmesartan, we measured urine monocyte chemoattractant protein-1 levels finding that, though not statistically significant, olmesartan tended to decrease urine monocyte chemoattractant protein-1 levels. Regarding EC-SOD, an antioxidative property of the vasculature, neither pre- nor postEC-SOD levels, or the resulting heparin-releasable EC-SOD levels were changed by either treatment.

Among 28 subjects in whom urine albumin levels could be determined, olmesartan significantly decreased the albumin:creatinine ratio compared with amlodipine despite their similar reductions of BP. Other oxidative stress markers in urine determined in this study were urine antioxidant capacity based on the scavenging of ABTS+radical cation and urine lipid peroxidation products and 8 -epi-PGF2 $\alpha$. Olmesartan significantly increased the former and decreased the latter while amlodipine did not affect either, indicating that olmesartan exhibited an anti-oxidative property in hypertensive patients.

Next, to further explore potential mechanisms underlying olmesartan-mediated restoration of endothelial function, we examined an association between $\% \Delta \mathrm{FMD}$ and $\% \Delta$ pre-heparin EC-SOD. As evident in Figure 2, there was a significant positive correlation between these parameters only for olmesartan. An increase in FMD because of olmesartan was also correlated with one in post-heparin EC-SOD ( $r^{2}=0.227, P=0.01$, data not shown), but not endothelium-bound heparin-releasable EC-SOD (data not shown), implying that the total amount of EC-SOD, rather than that of endothelium-bound EC-SOD in the vasculature is important for olmesartan induced changes in endothelial function. Changes in FMD were not associated with other parameters, including $\mathrm{BP} / \mathrm{HR}$ at office or home, renal function (creatinine, eGFR or albumin:creatinine ratio), oxidative stress (antioxidants or 8 -epi-PGF2 $\alpha$ ) and inflammation (hsCRP or urine monocyte chemoattractant protein-1) (data not shown). We also examined an association between baseline characteristics and improvement in FMD due to olmesartan. Subjects whose FMD was increased by olmesartan had higher hemoglobin Alc (5.1 \pm 0.2 vs. $5.5 \pm 0.7 \%, P<0.05)$ and homeostasis model assessment estimatedinsulin resistance $(0.9 \pm 0.6$ vs. $1.9 \pm 1.6, P<0.05)$ levels compared with those in whom FMD was decreased (data not shown). Other parameters at baseline were not associated with changes in FMD because of olmesartan.

\section{DISCUSSION}

The present study demonstrated that the ARB olmesartan improved endothelial function as compared with the calcium channel blocker amlodipine despite achieving similar BP reductions in hypertensive patients. Olmesartan also decreased serum hsCRP levels, urinary excretion of albumin and urine 8-epi-PGF $2 \alpha$ levels, and increased antioxidants in urine. Interestingly, olmesartan-mediated restoration of endothelial function was found to be significantly associated with an increase in pre- and post-heparin EC-SOD.

Previously, two trials comparing the effectiveness of ACEI and ARB regarding endothelial function in hypertensive patients produced mixed results. Ghiadoni et al. ${ }^{7}$ observed that ACEI, but not ARB, improved endothelial function; whereas Koh et al. ${ }^{26}$ reported that both ACEI and ARB increased FMD. The beneficial effect of ACEI on endothelial vasodilator function is reportedly mediated by a bradyki- 
Table 4 Biochemical parameters in blood and urine before and after treatments

\begin{tabular}{|c|c|c|c|c|c|c|}
\hline & Baseline & Olmesartan & Amlodipine & $\mathrm{P}$-value ${ }^{\mathrm{a}}$ & $\mathrm{P}$-value ${ }^{\mathrm{b}}$ & P-value ${ }^{c}$ \\
\hline \multicolumn{7}{|l|}{ Blood parameters } \\
\hline Total cholesterol, mg dl ${ }^{-1}$ & $200 \pm 36$ & $197 \pm 42$ & $197 \pm 42$ & 0.4 & 0.4 & 0.9 \\
\hline HDL-cholesterol, $\mathrm{mg} \mathrm{dl}^{-1}$ & $57 \pm 14$ & $56 \pm 14$ & $57 \pm 14$ & 0.5 & 0.7 & 0.5 \\
\hline $\mathrm{FBS}, \mathrm{mg} \mathrm{dl}^{-1}$ & $103 \pm 19$ & $97 \pm 14$ & $97 \pm 13$ & 0.1 & 0.07 & 0.9 \\
\hline $\mathrm{HbA} 1 \mathrm{c}, \%$ & $5.4 \pm 0.6$ & $5.3 \pm 0.4$ & $5.2 \pm 0.4$ & 0.2 & 0.3 & 0.5 \\
\hline Creatinine, $\mathrm{mg} \mathrm{dl}^{-1}$ & $0.76 \pm 0.17$ & $0.79 \pm 0.17$ & $0.75 \pm 0.17$ & 0.034 & 0.7 & 0.016 \\
\hline eGFR, $\mathrm{ml} \mathrm{min}-11.73 \mathrm{~m}^{-2}$ & $83 \pm 16$ & $79 \pm 15$ & $84 \pm 18$ & 0.025 & 0.4 & 0.009 \\
\hline hsCRP, $\mathrm{mgl}^{-1}$ & $0.79(0.47,1.28)$ & $0.50(0.30,1.35)$ & $0.78(0.41,1.40)$ & 0.032 & 1.0 & 0.2 \\
\hline EC-SOD pre-heparin, $\mathrm{ng} \mathrm{ml}^{-1}$ & $73 \pm 40$ & $71 \pm 43$ & $74 \pm 43$ & 0.6 & 0.3 & 0.2 \\
\hline EC-SOD post-heparin, $\mathrm{ng} \mathrm{ml}^{-1}$ & $87 \pm 39$ & $88 \pm 44$ & $89 \pm 44$ & 0.4 & 0.4 & 0.8 \\
\hline EC-SOD heparin-releasable, $\mathrm{ng} \mathrm{ml}^{-1}$ & $14.0 \pm 10.3$ & $17.2 \pm 11.5$ & $15.0 \pm 8.9$ & 0.6 & 0.1 & 0.1 \\
\hline Antioxidants, mmol $\mathrm{I}^{-1}$ Trolox equivalent & $12.6 \pm 2.3$ & $13.9 \pm 2.4$ & $13.5 \pm 2.6$ & 0.02 & 0.08 & 0.6 \\
\hline MCP-1, $\mathrm{pg} \mathrm{ml}^{-1}$ & $304 \pm 238$ & $234 \pm 194$ & $284 \pm 180$ & 0.09 & 0.2 & 0.5 \\
\hline
\end{tabular}

Abbreviations: ACR, albumin:creatinine ratio; $\mathrm{Cr}$, creatinine; eGFR, estimated glomerular filtration rate; EC-SOD, extracellular superoxide dismutase; FBS, fasting blood sugar; HDL, high density-lipoprotein; HbA1c, hemoglobin Alc; HOMA-IR, homeostasis model assessment insulin resistance; hsCRP, high sensitive C-reactive protein; MCP-1, monocyte chemoatractant protein-1;

8 -epi-PGF $2 \alpha, 8$-epi-prostaglandin F2 $\alpha$.
Values are mean \pm s.d. except for triglycerides and hsCRP, presented as median (interquatile range). For ACR, results are from 28 subjects whose urine albumin levels were above detection limit.

Values are mean \pm s.d. except for triglycerides and
${ }^{a} P$-value for olmesartan treatment $v$ s. baseline.

${ }^{P} P$-value for amlodipine treatment $v$ s. baseline.

${ }^{c} P$-value for olmesartan treatment $v s$. amlodipine.
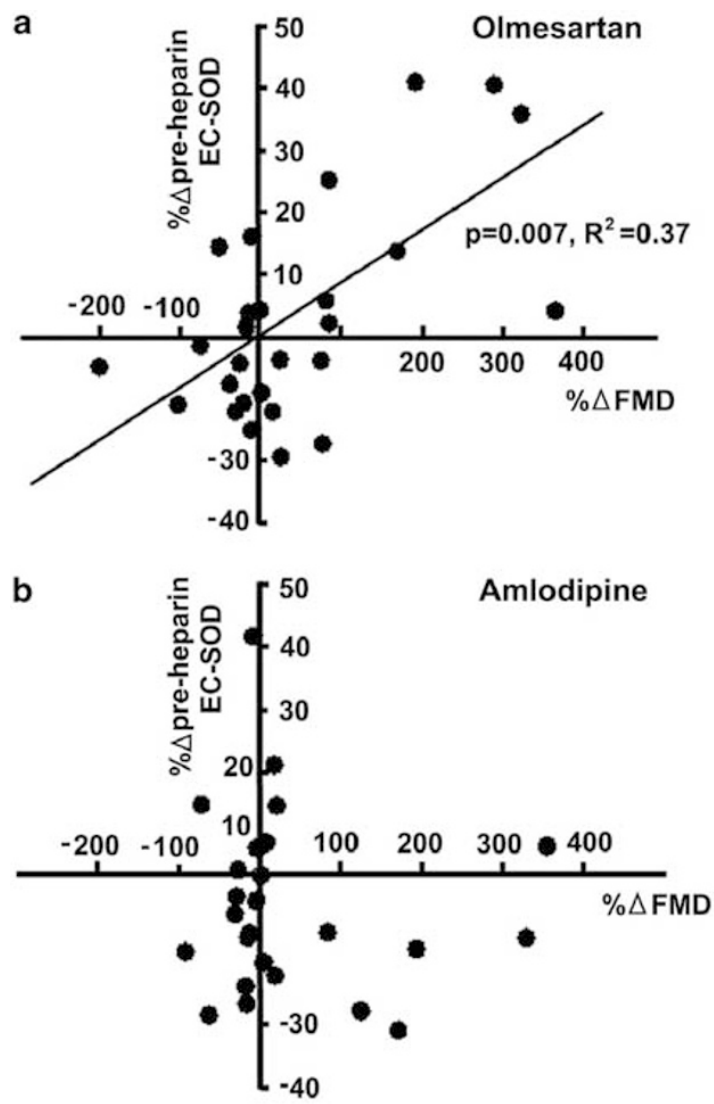

Figure 2 Correlations between percent change in flow-mediated vasodilation (FMD) and pre-heparin EC-SOD after treatment with olmesartan or amlodipine. Values after the treatment with $\mathbf{a}$, olmesartan or $\mathbf{b}$, amlodipine. nin-dependent pathway where ACEI directly inhibits bradykinin degradation by ACE. ${ }^{27}$ ARB-mediated improvement of NO availability is also known to be indirectly mediated by bradykinin: ARB stimulates prostacyclin production and Ang II type 2 receptor, resulting in bradykinin B (2)-receptor activation. ${ }^{28}$ In addition, both treatments prevent increased NO inactivation due to oxygen radicals by reducing Ang II type 1-receptor-dependent activation of the oxidant enzyme NADPH oxidase and enhancing EC-SOD activity. ${ }^{29}$ Furthermore, an Ang II infusion reportedly resulted in increased superoxide anion production and NADPH-dependent oxidase activity, ${ }^{30}$ leading to endothelial dysfunction in animal experiments, ${ }^{31}$ though endothelial responses were restored by treatment with superoxide dismutase or ARB. ${ }^{31}$ Recently, an improvement of endothelial dysfunction in hypertension has been reported to be associated with ACE2, a newly recognized homolog of ACE. ACE2 converts Ang II to angiotensin-1-7 (Ang-(1-7)), which increased NO release from endothelial cells through its receptor Mas, thus resulting in vasodilation. ${ }^{32}$ As olmesartan reportedly increased aortic ACE2 and Ang-(1-7) in conjunction with improved vascular remodeling in spontaneously hypertensive rats, ${ }^{33}$ the effect of olmesartan on endothelial function might be mediated by this pathway. In the present study, olmesartan significantly improved endothelial function as compared with baseline and amlodipine (Table 3). In contrast, while amlodipine brought about a similar reduction in BP to olmesartan, it did not affect FMD, indicating that the olmesartan-mediated effect on FMD was independent of BP reduction.

EC-SOD is a major antioxidant enzyme, which is widely distributed in the extracellular matrix of tissues, especially in the vasculature. ${ }^{34}$ EC-SOD is anchored to heparan sulfate proteoglycans on endothelial cells and released by treatment with heparin in vitro and in vivo. Landmesser et al. ${ }^{35}$ reported that heparin-releasable (that is, endothelium-bound) EC-SOD activity was substantially reduced in patients 
with coronary artery disease, as well as a close relationship between endothelium-bound EC-SOD activity and endothelial function. They also demonstrated that ACEI and ARB improved endothelial function in the radial artery by increasing endothelium-bound EC-SOD activity. ${ }^{6}$ Furthermore, the beneficial effects of ACEI/ARB on endothelial function were canceled under the co-administration of vitamin C. ${ }^{6}$ These observations imply that EC-SOD bound to endothelium primarily contributes to improvement of endothelial function by increasing NO bioavailability through its antioxidative property. In the present study, olmesartan improved FMD, but did not affect pre- or post heparin-releasable EC-SOD. This discrepancy might be because: (1) we measured expression levels of EC-SOD using ELISA, not SOD activity, (2) total amounts of injected heparin were less than those reported by Hornig et al. ${ }^{6}\left(30 \mathrm{IU} \mathrm{kg}^{-1}\right.$ vs. $\left.5000 \mathrm{IU}\right)$. Interestingly, we found that changes in pre- and post-heparin EC-SOD levels after olmesartan treatment were significantly and positively correlated with those in FMD, indicating the possibility that olmesartan may improve FMD by increasing EC-SOD to some degree, though these changes did not translate into overall changes in pre- and post-heparin EC-SOD levels. These observations are similar to those reported by Naya et al. $^{36}$ who found that olmesartan, but not amlodipine, improved endothelium-dependent coronary dilation in hypertensive patients and there was a significant correlation between the changes in endothelial function and SOD levels.

Deterioration in renal function, namely chronic kidney disease, is associated with increased cardiovascular morbidity and mortality in the general population and various patient settings. ${ }^{37}$ Perticone et al. ${ }^{13}$ demonstrated that an impaired endothelium-dependent vasodilatory response is associated with renal dysfunction in hypertensive patients. In the present study, olmesartan, but not amlodipine, significantly decreased eGFR. However, an initial decline in eGFR is reportedly minimized in several months and it eventually stabilizes within a few years, ${ }^{38}$ showing that renal function is protected. ${ }^{39}$ However, this response appears to be functional in nature and should be expected based on renal physiology (adaptive effect against reduction in glomerular BP) and its dependence on RAS in maintaining GFR. In this regard, it has been observed that early elevation of serum creatinine is associated with improved long-term renal outcomes. Furthermore, our finding that changes in eGFR were not associated with those in FMD indicates that initial reduction in GFR because of ARB is not harmful to endothelial function.

Microalbuminuria is reportedly associated with impaired endothelium-dependent, FMD in patients with or without diabetes. ${ }^{40}$ Prevailing experimental and clinical data suggest that generalized endothelial dysfunction, frequently characterized by decreased NO bioavailability, actually precedes the development of microalbuminuria. ${ }^{41}$ In the present study, olmesartan, but not amlodipine, significantly attenuated microalbuminuria, consistent with a previous study. ${ }^{42}$ However, improvement of FMD was not correlated with the changes in urinary excretion of albumin. Since microalbuminuria is reportedly attributable to various pathogenesis including inflammation and oxidative stress, parameters improved by olmesartan in this study, it is our opinion that such complexities may preclude a one-to-one relationship between endothelial function and microalbuminuria.

A growing wealth of evidence supports the paradigm that inflammation has a pivotal role in the development and progression of atherosclerosis. Several investigators clearly demonstrated that inflammatory mediators induced endothelial dysfunction. ${ }^{43}$ Qamirani et al. ${ }^{44}$ reported that CRP inhibits endothelium-dependent NOmediated dilation in coronary arterioles by producing superoxide from $\mathrm{NAD}(\mathrm{P}) \mathrm{H}$ oxidase through $\mathrm{p} 38$ kinase activation. The present study demonstrated that olmesartan significantly reduced serum hsCRP levels as previously reported..$^{25,45-47}$ However, the changes in hsCRP levels were not associated with those in FMD. As in the case of microalbuminuria, as RAS inhibition produces pleiotropic effects, there may not be a simple one-to-one correlation between serum hsCRP levels and endothelial function either.

\section{Study limitations}

First, this study was not blinded and had a small sample size, which represents a possible limitation. To deal with this potential bias, measurements were performed by investigators unaware of the randomization status. In addition, all measurements were recorded, and subsequently, vessel diameter and blood flow velocity were analyzed by two investigators unaware of the sequence of interventions or assignment to treatments. Second, there was no washout period, which would in theory yield a carry-over effect. The statistical analysis, however, showed no evidence of a carry-over or time sequence effect on the end points evaluated in this study, including BPs both at office and home, anthropometric parameters, laboratory parameters and FMD/NMD of brachial artery. Therefore, any carry-over effect in this study would have been minimal. Finally, as the study subjects included diabetic patients, they were a heterogeneous population. This would be a limitation as well as a strength. In a subgroup analysis, there was no difference in response for the various parameters between the whole group and non-diabetic subjects.

In conclusion, olmesartan improved endothelial dysfunction, which was associated with changes in EC-SOD, decreased serum CRP, and attenuated microalbuminuria and oxidative stress in hypertensive patients. These effects of olmesartan could constitute a beneficial cardioprotective property to supplement its BP-lowering effect.

\section{CONFLICT OF INTEREST}

The authors declare no conflict of interest.

1 Panza JA, Quyyumi AA, Brush Jr JE, Epstein SE. Abnormal endothelium-dependent vascular relaxation in patients with essential hypertension. N Engl J Med 1990; 323: 22-27.

2 Ghiadoni L, Taddei S, Virdis A, Sudano I, Di Legge V, Meola M, Di Venanzio L, Salvetti A Endothelial function and common carotid artery wall thickening in patients with essential hypertension. Hypertension 1998; 32: 25-32.

3 Taddei S, Salvetti A. Endothelial dysfunction in essential hypertension: clinical implications. J Hypertens 2002; 20: 1671-1674.

4 Schiffrin EL. Beyond blood pressure: the endothelium and atherosclerosis progression. Am J Hypertens 2002; 15: 115S-122S.

5 Al Khalaf MM, Thalib L, Doi SA. Cardiovascular outcomes in high-risk patients without heart failure treated with ARBs: a systematic review and meta-analysis. Am J Cardiovasc Drugs 2009; 9: 29-43.

6 Hornig B, Landmesser U, Kohler C, Ahlersmann D, Spiekermann S, Christoph A Tatge $\mathrm{H}$, Drexler $\mathrm{H}$. Comparative effect of ace inhibition and angiotensin II type 1 receptor antagonism on bioavailability of nitric oxide in patients with coronary artery disease: role of superoxide dismutase. Circulation 2001; 103: 799-805.

7 Ghiadoni L, Magagna A, Versari D, Kardasz I, Huang Y, Taddei S, Salvetti A. Different effect of antihypertensive drugs on conduit artery endothelial function. Hypertension 2003; 41: 1281-1286.

8 Oshima T, Ozono R, Yano Y, Higashi Y, Teragawa H, Miho N, Ishida T, Ishida M, Yoshizumi M, Kambe M. Beneficial effect of T-type calcium channel blockers on endothelial function in patients with essential hypertension. Hypertens Res 2005; 28: 889-894.

9 Androulakis ES, Tousoulis D, Papageorgiou N, Tsioufis C, Kallikazaros I, Stefanadis C. Essential hypertension: is there a role for inflammatory mechanisms? Cardiol Rev 2009; 17: $216-221$.

10 Forstermann U. Oxidative stress in vascular disease: causes, defense mechanisms and potential therapies. Nat Clin Pract Cardiovasc Med 2008; 5: 338-349.

11 Calver A, Collier J, Vallance P. Inhibition and stimulation of nitric oxide synthesis in the human forearm arterial bed of patients with insulin-dependent diabetes. J Clin Invest 1992; 90: 2548-2554.

12 Gilligan DM, Sack MN, Guetta V, Casino PR, Quyyumi AA, Rader DJ, Panza JA, Cannon III RO. Effect of antioxidant vitamins on low density lipoprotein oxidation and 
impaired endothelium-dependent vasodilation in patients with hypercholesterolemia. J Am Coll Cardiol 1994; 24: 1611-1617.

13 Perticone F, Maio R, Tripepi G, Zoccali C. Endothelial dysfunction and mild renal insufficiency in essential hypertension. Circulation 2004; 110: 821-825.

14 Imai Y, Otsuka K, Kawano Y, Shimada K, Hayashi H, Tochikubo O, Miyakawa M, Fukiyama K. Japanese society of hypertension (JSH) guidelines for self-monitoring of blood pressure at home. Hypertens Res 2003; 26: 771-782.

15 Shirasaki O, Terada H, Niwano K, Nakanishi T, Kanai M, Miyawaki Y, Souma T, Tanaka T, Kusunoki T. The Japan home-health apparatus industrial association: investigation of home-use electronic sphygmomanometers. Blood Press Monit 2001; 6: 303-307.

16 Corretti MC, Anderson TJ, Benjamin EJ, Celermajer D, Charbonneau F, Creager MA, Deanfield J, Drexler H, Gerhard-Herman M, Herrington D, Vallance P, Vita J, Vogel R. Guidelines for the ultrasound assessment of endothelial-dependent flow-mediated vasodilation of the brachial artery: a report of the international brachial artery reactivity task force. J Am Coll Cardiol 2002; 39: 257-265.

17 Uehata A, Lieberman EH, Gerhard MD, Anderson TJ, Ganz P, Polak JF, Creager MA Yeung AC. Noninvasive assessment of endothelium-dependent flow-mediated dilation of the brachial artery. Vasc Med 1997; 2: 87-92.

18 Adachi T, Ohta H, Yamada H, Futenma A, Kato K, Hirano K. Quantitative analysis of extracellular-superoxide dismutase in serum and urine by ELISA with monoclonal antibody. Clin Chim Acta 1992; 212: 89-102.

19 Matthews DR, Hosker JP, Rudenski AS, Naylor BA, Treacher DF, Turner RC. Homeostasis model assessment: insulin resistance and beta-cell function from fasting plasma glucose and insulin concentrations in man. Diabetologia 1985; 28: 412-419.

20 Miller NJ, Rice-Evans C, Davies MJ, Gopinathan V, Milner A. A novel method for measuring antioxidant capacity and its application to monitoring the antioxidant status in premature neonates. Clin Sci (Lond) 1993; 84: 407-412.

21 Morrow JD, Harris TM, Roberts II LJ. Noncyclooxygenase oxidative formation of a series of novel prostaglandins: analytical ramifications for measurement of eicosanoids. Anal Biochem 1990; 184: 1-10.

22 Matsuo S, Imai E, Horio M, Yasuda Y, Tomita K, Nitta K, Yamagata K, Tomino Y, Yokoyama $\mathrm{H}$, Hishida A. Revised equations for estimated GFR from serum creatinine in Japan. Am J Kidney Dis 2009; 53: 982-992.

23 Chrysant SG, Marbury TC, Robinson TD. Antihypertensive efficacy and safety of olmesartan medoxomil compared with amlodipine for mild-to-moderate hypertension. J Hum Hypertens 2003; 17: 425-432.

24 Kimura Y, Matsumoto M, Den YB, Iwai K, Munehira J, Hattori H, Hoshino T, Yamada K, Kawanishi K, Tsuchiya H. Impaired endothelial function in hypertensive elderly patients evaluated by high resolution ultrasonography. Can J Cardiol 1999; 15: 563-568.

25 Fliser D, Buchholz K, Haller H. Antiinflammatory effects of angiotensin II subtype 1 receptor blockade in hypertensive patients with microinflammation. Circulation 2004; 110: 1103-1107.

26 Koh KK, Quon MJ, Han SH, Lee Y, Kim SJ, Koh Y, Shin EK. Distinct vascular and metabolic effects of different classes of anti-hypertensive drugs. Int J Cardiol 2010; 140: 73-81.

27 Landmesser U, Drexler H. Effect of angiotensin II type 1 receptor antagonism on endothelial function: role of bradykinin and nitric oxide. J Hypertens Supp/ 2006; 24: S39-S43.

28 De Gennaro Colonna V, Rigamonti A, Fioretti S, Bonomo S, Manfredi B, Ferrario P, Bianchi M, Berti F, Muller EE, Rossoni G. Angiotensin-converting enzyme inhibition and angiotensin AT1-receptor antagonism equally improve endothelial vasodilator function in L-NAME-induced hypertensive rats. Eur J Pharmacol 2005; 516: 253-259.

29 Griendling KK, Sorescu D, Lassegue B, Ushio-Fukai M. Modulation of protein kinase activity and gene expression by reactive oxygen species and their role in vascular physiology and pathophysiology. Arterioscler Thromb Vasc Biol 2000; 20: 2175-2183.

30 Rajagopalan S, Kurz S, Munzel T, Tarpey M, Freeman BA, Griendling KK, Harrison DG. Angiotensin II-mediated hypertension in the rat increases vascular superoxide produc- tion via membrane NADH/NADPH oxidase activation. Contribution to alterations of vasomotor tone. J Clin Invest 1996; 97: 1916-1923.

31 Prasad A, Tupas-Habib T, Schenke WH, Mincemoyer R, Panza JA, Waclawin MA, Ellahham S, Quyyumi AA. Acute and chronic angiotensin-1 receptor antagonism reverses endothelial dysfunction in atherosclerosis. Circulation 2000; 101: 2349-2354.

32 Rabelo LA, Alenina N, Bader M. ACE2-angiotensin-(1-7)-mas axis and oxidative stress in cardiovascular disease. Hypertens Res 2011; 34: 154-160.

33 Igase M, Kohara K, Nagai T, Miki T, Ferrario CM. Increased expression of angiotensin converting enzyme 2 in conjunction with reduction of neointima by angiotensin II type 1 receptor blockade. Hypertens Res 2008; 31: 553-559.

34 Stralin P, Karlsson K, Johansson BO, Marklund SL. The interstitium of the human arterial wall contains very large amounts of extracellular superoxide dismutase. Arterioscler Thromb Vasc Biol 1995; 15: 2032-2036.

35 Landmesser U, Merten R, Spiekermann S, Buttner K, Drexler H, Hornig B. Vascular extracellular superoxide dismutase activity in patients with coronary artery disease: relation to endothelium-dependent vasodilation. Circulation 2000; 101: 2264-2270.

36 Naya M, Tsukamoto T, Morita K, Katoh C, Furumoto T, Fujii S, Tamaki N, Tsutsui H. Olmesartan, but not amlodipine, improves endothelium-dependent coronary dilation in hypertensive patients. J Am Coll Cardiol 2007; 50: 1144-1149.

37 Go AS, Chertow GM, Fan D, McCulloch CE, Hsu CY. Chronic kidney disease and the risks of death, cardiovascular events, and hospitalization. N Engl J Med 2004; 351: 1296-1305.

38 Barnett A. Prevention of loss of renal function over time in patients with diabetic nephropathy. Am J Med 2006; 119: S40-S47.

39 Brenner BM, Cooper ME, de Zeeuw D, Keane WF, Mitch WE, Parving HH, Remuzzi G, Snapinn SM, Zhang Z, Shahinfar S. Effects of losartan on renal and cardiovascular outcomes in patients with type 2 diabetes and nephropathy. N Engl J Med 2001; 345: 861-869.

40 Stehouwer CD, Henry RM, Dekker JM, Nijpels G, Heine RJ, Bouter LM. Microalbuminuria is associated with impaired brachial artery, flow-mediated vasodilation in elderly individuals without and with diabetes: further evidence for a link between microalbuminuria and endothelial dysfunction—-the Hoorn Study. Kidney Int Supp/ 2004; 92 : S42-S44.

41 Ochodnicky P, Henning RH, van Dokkum RP, de Zeeuw D. Microalbuminuria and endothelial dysfunction: emerging targets for primary prevention of end-organ damage. J Cardiovasc Pharmacol 2006; 47 (Suppl 2): S151-S162; discussion S172-S176.

42 Ikeda H, Hamamoto Y, Honjo S, Nabe K, Wada Y, Koshiyama H. Olmesartan reduced microalbuminuria in Japanese subjects with type 2 diabetes. Diabetes Res Clin Pract 2009; 83: 117-118.

43 Zhang C. The role of inflammatory cytokines in endothelial dysfunction. Basic Res Cardiol 2008; 103: 398-406.

44 Qamirani E, Ren Y, Kuo L, Hein TW. C-reactive protein inhibits endothelium-dependent NO-mediated dilation in coronary arterioles by activating p38 kinase and $\mathrm{NAD}(\mathrm{P}) \mathrm{H}$ oxidase. Arterioscler Thromb Vasc Biol 2005; 25: 995-1001.

45 Sugihara M, Miura S, Takamiya Y, Kiya Y, Arimura T, Iwata A, Kawamura A, Nishikawa H, Uehara Y, Saku K. Safety and efficacy of antihypertensive therapy with add-on angiotensin II type 1 receptor blocker after successful coronary stent implantation. Hypertens Res 2009; 32: 625-630.

46 Derosa G, Maffioli P, Salvadeo SA, Ferrari I, Gravina A, Mereu R, Palumbo I, Fogari E, D'Angelo A, Cicero AF. Differential effects of candesartan and olmesartan on adipose tissue activity biomarkers in type II diabetic hypertensive patients. Hypertens Res 2010; 33: 790-795.

47 Nakayama S, Watada H, Mita T, Ikeda F, Shimizu T, Uchino H, Fujitani Y, Hirose T, Kawamori R. Comparison of effects of olmesartan and telmisartan on blood pressure and metabolic parameters in Japanese early-stage type-2 diabetics with hypertension. Hypertens Res 2008; 31: 7-13. 